\title{
Cardiovascular safety of lumiracoxib: a meta-analysis of randomised controlled trials in patients with osteoarthritis
}

\author{
Isla S. Mackenzie • Li Wei • Thomas M. MacDonald
}

Received: 17 February 2012 / Accepted: 7 June 2012 /Published online: 26 June 2012

(C) The Author(s) 2012. This article is published with open access at Springerlink.com

\begin{abstract}
Purpose To re-evaluate the cardiovascular risk of lumiracoxib compared with other non-steroidal anti-inflammatory drugs (NSAIDs) or placebo in patients with osteoarthritis. Methods We conducted a meta-analysis of randomised controlled trials of lumiracoxib versus placebo or other NSAIDs in patients with osteoarthritis reported up to January 2010. Both published and unpublished trials were included. PubMed searches using predefined search criteria (lumiracoxib AND osteoarthritis, limits: none; COX-189 AND osteoarthritis, limits: none) were used to obtain the relevant published trials. Novartis granted explicit access to their company studies and the right to use these study reports for the purposes of publication in peer reviewed journals. Endpoints were the Antiplatelet Trialists' Collaboration (APTC) endpoint and individual cardiovascular endpoints. Results Meta-analysis of 6 trials of lumiracoxib versus placebo revealed no difference in cardiovascular outcomes. Meta-analysis of 12 trials of lumiracoxib versus other NSAIDs also revealed no difference. The pooled odds ratios were: 1.16 (95\% CI 0.82, 1.63); 1.66 (95\% CI 0.84, 3.29); 0.95 (95\% CI $0.52,1.76)$ and 1.04 (95\% CI $0.60,1.80)$ for the APTC endpoint, myocardial infarction, stroke and cardiovascular death respectively.

Conclusions The results suggest that there were no significant differences in cardiovascular outcomes between lumiracoxib and placebo or between lumiracoxib and other NSAIDs in patients with osteoarthritis. Wide confidence intervals mean that further research is needed in this area to confirm these findings.
\end{abstract}

\footnotetext{
I. S. Mackenzie $(\triangle) \cdot$ L. Wei $\cdot$ T. M. MacDonald

Medicines Monitoring Unit (MEMO) \& Hypertension Research

Centre (HRC), Division of Medical Sciences, University of

Dundee, Ninewells Hospital \& Medical School,

Dundee DD1 9SY, UK

e-mail: i.s.mackenzie@dundee.ac.uk
}

Keywords Lumiracoxib · Cyclooxygenase · NSAIDs · Cardiovascular $\cdot$ Osteoarthritis $\cdot$ Hypertension

\section{Introduction}

Lumiracoxib (COX-189) is a cyclooxygenase type 2 (COX2) inhibitor and non-steroidal anti-inflammatory drug (NSAID) used for the treatment of osteoarthritis and acute pain. As a group, NSAIDs, including both traditional nonselective NSAIDs and COX-2 selective inhibitors, have been associated with increased risk of cardiovascular events [1]. Possible mechanisms have been debated widely and probably include effects on platelet function, blood pressure and sodium retention.

Different NSAIDs have different effects on specific cardiovascular parameters such as blood pressure. Lumiracoxib may have certain advantages over other NSAIDs in terms of its effects on blood pressure [2,3]. However, lumiracoxib has been associated with severe liver injury in a small number of patients, some of whom required liver transplantation. In many of these cases other risk factors for liver disease were also present and it was not clear whether the liver injury was drug-induced. The result was that lumiracoxib was withdrawn from several worldwide markets from 2007 onwards and it also failed to gain approval in other countries because of the potential for hepatotoxicity. Recently, a genome-wide association (GWA) study identified HLA alleles strongly associated with risk of hepatotoxicity with lumiracoxib, opening up the possibility of pretreatment pharmacogenetic screening to exclude patients at higher risk of liver injury from lumiracoxib treatment [4].

This paper re-evaluates the cardiovascular safety of lumiracoxib in patients with osteoarthritis in comparison to other NSAIDs and placebo at a time when it looks possible that lumiracoxib might re-emerge on to the market alongside a 
pharmacogenomic screening test to target its use more safely.

\section{Materials and methods}

A systematic review of clinical trials of lumiracoxib in patients with osteoarthritis reported up to January 2010 was undertaken. Trials were included if they used lumiracoxib daily doses of 100-400 mg, were of at least 1 week's duration and if they had a substantial cardiovascular component. Both published and unpublished trials were included. Novartis granted explicit access to their company studies and the right to use these study reports for the purposes of publication in peer reviewed journals. PubMed searches using predefined search criteria (lumiracoxib AND osteoarthritis, limits: none; COX-189 AND osteoarthritis, limits: none) were used to obtain the relevant published trials. Where both were available, published papers were matched to the relevant company clinical study reports to avoid double inclusion of the same study data. Each study was graded according to the quality of evidence using an appropriate validated grading system, the Jadad scale [5]. Only studies judged to be of sufficient quality (Jadad score $>3$ ) were included in the evaluation. The list of published trials and clinical study reports with Jadad scores $>3$ that were included for detailed review and meta-analysis in this report is presented in Table 1. Cardiovascular events were the primary outcome for only one study [6] and were reported as adverse events in others. Adverse events were reviewed by an independent safety committee in a blinded manner for 4 studies [2, 6-8]. In the other studies AEs were reported as recorded by investigators or subjects. All patients had to meet the inclusion criterion of primary osteoarthritis and patients who had secondary osteoarthritis, other connective tissue diseases, or significant medical problems were excluded from the studies. The average age of the study participants in Table 1 ranged from 59.5 to 65.5 years old and there were more women than men in the studies (ranging from $59 \%$ to $76 \%$ across the studies). Safety assessment was carried out for the duration of the studies. One study reported a safety assessment lasting 2 weeks after the end of study. The studies that were considered but excluded are listed in Table 2, along with the Jadad scores assigned and the reasons for exclusion. The initial search of studies and Jadad score assignment were carried out by Chameleon Communications International under our instruction. We subsequently independently reviewed and approved this work.

Cardiovascular endpoints of relevance to the present paper primarily included the Antiplatelet Trialists' Collaboration (APTC) events (non-fatal myocardial infarction [MI], non-fatal stroke or cardiovascular death). However, each of the APTC components was also considered separately where data were available. Tabulations of the events of interest and crude event rates were abstracted. Subject level data were generally not available, although some descriptions of individual serious adverse events and deaths were provided in clinical study reports. Overall crude summary statistics were constructed.

\section{Data extraction}

Data extraction from the published studies and clinical study reports was performed by one author and checked by the other authors. Although in many cases, there was clear reporting of numbers of events, in a few cases, a value judgement had to be applied as to whether to include events or not, for example, when events occurred soon after completion of the study.

\section{Statistical analysis}

The odds ratio (OR) and 95\% confidence intervals (CIs) were calculated for each trial based on the total number of patients and total number of events in each group. The fixed effects model was used to obtain pooled ORs after a heterogeneity test among the trials. Publication bias was assessed by Egger's test and Begg's funnel plots for each of the endpoints studied by meta-analysis and no bias was found. The meta-analysis was conducted using StatsDirect software.

\section{Results}

Characteristics of the studies included in the review

All the studies included were randomised controlled trials in patients with osteoarthritis. All studies were of lumiracoxib versus placebo or lumiracoxib versus one or more active NSAID comparators (or both placebo and NSAID comparator). Doses of lumiracoxib were between $50 \mathrm{mg}$ twice daily and $400 \mathrm{mg}$ once daily (total daily doses 100-400 mg). Comparator NSAIDs in the studies included ibuprofen, celecoxib, naproxen, rofecoxib and diclofenac. The duration of drug therapy in the studies was from 1 week to 1 year. All the studies included were of sufficient quality to be graded with a Jadad score of $>3$. Of the 19 studies included, 7 were reported as both published journal articles and clinical study reports $[2,6-9,10-12]$ and the remainder were reported only in unpublished Novartis clinical study reports. Where both the published journal article and the original clinical study reports were available pertaining to the same data, both reports were reviewed, but the data were only included once. 
Table 1 List of studies included for review

\begin{tabular}{|c|c|c|c|c|c|c|}
\hline $\begin{array}{l}\text { Reference } \\
\text { (published studies) }\end{array}$ & $\begin{array}{l}\text { Study number (Novartis } \\
\text { clinical study reports) }\end{array}$ & $\begin{array}{l}\text { Total number } \\
\text { of patients }\end{array}$ & $\begin{array}{l}\text { Lumiracoxib dose } \\
\text { (number of patients) }\end{array}$ & $\begin{array}{l}\text { Comparator NSAIDs and } \\
\text { dose (number of patients) }\end{array}$ & $\begin{array}{l}\text { Exposure } \\
\text { duration (days) }\end{array}$ & $\begin{array}{l}\text { Jadad } \\
\text { score }\end{array}$ \\
\hline [9] & CSR104 & 583 & $\begin{array}{l}50 \mathrm{mg} \text { bd (98) } \\
100 \mathrm{mg} \text { bd (96) } \\
200 \mathrm{mg} \text { bd (99) } \\
400 \mathrm{mg} \text { od (99) }\end{array}$ & $\begin{array}{l}\text { Placebo (97) } \\
\text { Diclofenac } 75 \text { mg bd (94) }\end{array}$ & 28 & $4^{\mathrm{a}} / 5$ \\
\hline- & CSR109 & 1,600 & $\begin{array}{l}200 \mathrm{mg} \text { od }(462) \\
400 \mathrm{mg} \text { od }(463)\end{array}$ & $\begin{array}{l}\text { Placebo (231) } \\
\text { Celecoxib } 200 \text { mg od (444) }\end{array}$ & 91 & 5 \\
\hline$[10]$ & CSR112 & 1,702 & $\begin{array}{l}200 \mathrm{mg} \text { od (487) } \\
400 \mathrm{mg} \text { od (491) }\end{array}$ & $\begin{array}{l}\text { Placebo (243) } \\
\text { Celecoxib } 200 \text { mg od (481) }\end{array}$ & 91 & $4^{\mathrm{a}} / 5$ \\
\hline- & CSR112E & 1,235 & $\begin{array}{l}200 \mathrm{mg} \text { od (411) } \\
400 \mathrm{mg} \text { od (419) }\end{array}$ & Celecoxib $200 \mathrm{mg}$ od (405) & 273 & 5 \\
\hline- & CSR126 & 1,042 & $\begin{array}{l}200 \mathrm{mg} \text { od }(264) \\
400 \mathrm{mg} \text { od }(260)\end{array}$ & $\begin{array}{l}\text { Ibuprofen } 800 \mathrm{mg} \text { tds (260) } \\
\text { Celecoxib } 200 \mathrm{mg} \text { od (258) }\end{array}$ & 91 & 5 \\
\hline- & CSR128 & 511 & $400 \mathrm{mg}$ od (205) & $\begin{array}{l}\text { Placebo (204) } \\
\text { Rofecoxib } 25 \text { mg od (102) }\end{array}$ & 91 & 5 \\
\hline- & CSR2301 & 364 & $400 \mathrm{mg}$ od (144) & $\begin{array}{l}\text { Placebo (75) } \\
\text { Celecoxib } 200 \text { mg bd (145) }\end{array}$ & 7 & 5 \\
\hline- & CSR2303 & 408 & $\begin{array}{l}200 \mathrm{mg} \text { od (105) } \\
400 \mathrm{mg} \text { od (99) }\end{array}$ & $\begin{array}{l}\text { Placebo (103) } \\
\text { Celecoxib } 200 \text { mg bd (101) }\end{array}$ & 7 & 5 \\
\hline$[11]$ & CSR2307 & 309 & $400 \mathrm{mg}$ od (154) & Rofecoxib 25 mg od (155) & 42 & $5^{\mathrm{a}} / 5$ \\
\hline- & CSR2316 & 244 & $100 \mathrm{mg}$ od (122) & Placebo (122) & 28 & 5 \\
\hline- & CSR2319 & 594 & $\begin{array}{l}200 \mathrm{mg} \text { od (205) } \\
400 \mathrm{mg} \text { od (193) }\end{array}$ & Placebo (196) & 28 & 5 \\
\hline [7] & CSR2360 & 1,551 & $\begin{array}{l}100 \mathrm{mg} \text { od (391) } \\
200 \mathrm{mg} \text { od (385) }\end{array}$ & $\begin{array}{l}\text { Placebo (382) } \\
\text { Celecoxib } 200 \mathrm{mg} \text { od (393) }\end{array}$ & 91 & $5^{\mathrm{a}} / 5$ \\
\hline [8] & CSR2361 & 1,684 & $\begin{array}{l}100 \mathrm{mg} \text { od }(420) \\
200 \mathrm{mg} \text { od }(420)\end{array}$ & $\begin{array}{l}\text { Placebo (424) } \\
\text { Celecoxib } 200 \text { mg od (420) }\end{array}$ & 91 & $5^{\mathrm{a}} / 5$ \\
\hline- & CSR2361E & 1,310 & $100 \mathrm{mg}$ od (853) & Celecoxib 200 mg od (457) & 273 & 5 \\
\hline- & CSR2364 & 703 & $200 \mathrm{mg}$ od (352) & Celecoxib $200 \mathrm{mg}$ od (351) & 42 & 5 \\
\hline- & CSR2367 & 1,262 & $100 \mathrm{mg}$ od (427) & $\begin{array}{l}\text { Placebo (416) } \\
\text { Celecoxib } 200 \text { mg od (419) }\end{array}$ & 91 & 5 \\
\hline- & CSR2369 & 3,036 & $\begin{array}{l}100 \mathrm{mg} \text { od }(757) \\
100 \mathrm{mg} \text { bd }(1,520)\end{array}$ & Celecoxib $200 \mathrm{mg}$ od (759) & 364 & 5 \\
\hline$[2]$ & CSR2428 & 787 & 100 mg od (394) & Ibuprofen $600 \mathrm{mg}$ tds (393) & 28 & $5^{\mathrm{a} / 5}$ \\
\hline [6] & TARGET 0117 and 2332 & 18,325 & $400 \mathrm{mg}$ od $(9,156)$ & $\begin{array}{l}\text { Ibuprofen } 800 \mathrm{mg} \text { tds }(4,415) \\
\text { Naproxen } 500 \mathrm{mg} \text { bd }(4,754)\end{array}$ & 365 & $5^{\mathrm{a}} / 5$ \\
\hline
\end{tabular}

bd = twice daily; NSAID = non-steroidal anti-inflammatory drug; od = once daily; tds = three times daily

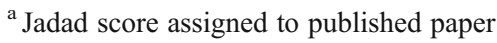

Randomised controlled trials of lumiracoxib versus placebo

Of the studies included, 11 out of 19 compared lumiracoxib with placebo; only 6 of these reported the occurrence of any APTC events and event numbers were very small, providing limited data for further analysis. Other cardiovascular endpoints were not reported consistently among studies and again, numbers of events were very small. Therefore, meta-analysis was limited to the APTC endpoints for this group of trials and was not conducted for any other individual cardiovascular outcomes.
The 6 studies comparing lumiracoxib versus placebo and reporting any APTC events are listed in Table 3. Only 6 APTC events were recorded in 4,122 lumiracoxib users and 1 APTC event in 1,680 placebo users. In total, there were 959 person-years' exposure to lumiracoxib and 385 personyears' exposure to placebo within this group of studies. The meta-analysis from the 6 trials revealed no significant difference in the incidence of APTC endpoints between lumiracoxib and placebo (pooled OR 1.10, 95\% CI 0.31, 3.94). However, the wide confidence intervals did not exclude lumiracoxib being almost $70 \%$ better than placebo or $394 \%$ worse than placebo. 
Table 2 List of all studies considered and excluded with Jadad scores and reasons for exclusion

\begin{tabular}{|c|c|c|}
\hline Reference & Jadad score & Reason for exclusion (if applicable) \\
\hline \multicolumn{3}{|l|}{ Published studies } \\
\hline Fleischmann, R et al. BMC Musculoskelet Disord 2008;9:32 & 1 & Jadad score $\leq 3$ \\
\hline Bin, Seong-II et al. APLAR J Rheumatol 2007;10:190 & 3 & Jadad score $\leq 3$ \\
\hline Farkouh, ME et al. J Clin Hypertens (Greenwich) 2008;10:592 & Not applicable & Post-hoc analysis of data in Farkouh et al .2004 \\
\hline Farkouh, ME et al. Ann Rheum Dis 2007;66:764 & Not applicable & Extended report of data in Farkouh et al. 2004 \\
\hline Kyle, C et al. Int J Clin Pract 2008;62:1684 & 4 & No significant $\mathrm{CV}$ component \\
\hline Sheldon, EA et al. Clin Exp Rheumatol 2008;26:611 & 2 & No significant $\mathrm{CV}$ component \\
\hline Wittenberg, RH et al. Arthritis Res Ther 2006;8:R35 & 3 & No significant $\mathrm{CV}$ component \\
\hline Dougados, M et al. Arthritis Res Ther 2006;9:R11 & 5 & No significant $\mathrm{CV}$ component \\
\hline Fleischmann, R et al. Clin Rheumatol 2006;25:42 & 3 & No significant $\mathrm{CV}$ component \\
\hline Grifka, JK et al. Clin Exp Rheumatol 2004;22:589 & 3 & No significant $\mathrm{CV}$ component \\
\hline Hawkey, CJ et al. Aliment Pharmacol Ther 2008;27:838 & 5 & No significant $\mathrm{CV}$ component \\
\hline Hawkey, CJ et al. Gastroenterology 2007;133:57 & Not applicable & No significant $\mathrm{CV}$ component \\
\hline Schnitzer, TJ et al. Lancet 2004;364:665 & 5 & No significant $\mathrm{CV}$ component \\
\hline Schnitzer, TJ et al. Curr Med Res Opin 2005;21:151 & 2 & Combined analysis \\
\hline Matchaba, P et al. Clin Ther 2005;27:1196 & Not applicable & Meta-analysis \\
\hline Chen, YF et al. Health Technol Assess 2008;12:1 & 0 & Study in patients with RA \\
\hline Hawkey, CJ et al. Clin Gastroenterol Hepatol 2006;4:57 & Not applicable & Study in patients with RA \\
\hline Nielsen, OH et al. Aliment Pharmacol Ther 2006;23:27 & 0 & Study in patients with RA \\
\hline Berenbaum, F et al. J Int Med Res 2005;33:21 & 3 & In vitro study \\
\hline Geusens, P et al. Int J Clin Pract 2004;58:1033 & 3 & Study in patients with RA \\
\hline Kivitz, AJ et al. Aliment Pharmacol Ther 2004;19:1189 & 3 & Study in patients with RA \\
\hline Scott, G et al. Clin Pharmacokinet 2004;43:467 & 0 & Study in patients with RA \\
\hline Kang, P et al. Chem Res Toxicol 2009;22:106 & 0 & In vitro study \\
\hline Laine, L et al. Semin Arthritis Rheum 2008;38:165 & 0 & Review article \\
\hline Shi, S et al. Eur J Clin Pharmacol 2008;64:233 & 0 & Review article \\
\hline Aust Nurs J 2007;15:8 [no authors listed] & 0 & Commentary \\
\hline Burton, B et al. BMJ 2007;335:363 & 0 & Commentary \\
\hline Baraf, HS et al. Curr Pharm Des 2007;13:2228 & 0 & Review article \\
\hline Bannwarth, B et al. Expert Opin Pharmacother 2007;8:1551 & 0 & Review article \\
\hline Hochberg, MC et al. Curr Top Med Chem 2005;5:443 & 0 & Review article \\
\hline Bannwarth, B et al. Expert Opin Investig Drugs 2005;14:521 & 0 & Review article \\
\hline Z Orthop Ihre Grenzgeb 2005;143:158 [no authors listed] & Not applicable & Article not in English \\
\hline Rordorf, CM et al. Clin Pharmacokinet 2005;44:1247 & 0 & Review article \\
\hline Rosenberg, JA et al. Nat Clin Pract Gasteroenterol Hepatol 2005;2:14 & 0 & Review article \\
\hline Hart, L et al. ACP J Club 2005;142:46 & 0 & Commentary \\
\hline Health News 2004;10:13 [no authors listed] & 0 & Commentary \\
\hline Kiefer, W et al. Curr Med Chem 2004;11:3147 & 0 & Review article \\
\hline Summerton, N et al. Br J Gen Pract 2004;54:880 & 0 & Review article \\
\hline Lyseng-Williamson, KA et al. Drugs 2004;64:2237 & 0 & Review article \\
\hline Hawkey, CC et al. J Rheumatol 2004;31:1804 & 0 & Review article \\
\hline Lazzaroni, M et al. Aliment Pharmacol Ther 2004;20:48 & 0 & Review article \\
\hline Topol, EJ et al. Lancet 2004;364:639 & 0 & Commentary \\
\hline Mysler, E et al. Int J Clin Pract 2004;58:606 & 0 & Review article \\
\hline Hawkey, CJ et al. Aliment Pharmacol Ther 2004;20:51 & 0 & Trial design only \\
\hline Mangold, JB et al. Drug Metab Dispos 2004;32:566 & 0 & Study in healthy volunteers \\
\hline Tacconelli, S et al. Curr Pharm Res 2004;10:589 & 0 & Review article \\
\hline Capone, ML et al. Int J Immunopathol Phramacol 2003;16:49 & 0 & Review article \\
\hline Ding, C et al. IDrugs 2002;5:1168 & 0 & Review article \\
\hline
\end{tabular}


Table 2 (continued)

\begin{tabular}{|c|c|c|}
\hline Reference & Jadad score & Reason for exclusion (if applicable) \\
\hline Buvanendran, A et al. Drugs Today (Barc) 2007;43:137 & 0 & Review Article \\
\hline Ker, J et al. Cardiovasc J Afr 2007;18:383 & 0 & Case study \\
\hline \multicolumn{3}{|l|}{ EULAR abstracts } \\
\hline Fleischmann, R et al. EULAR 2003 Poster FRI0233 & 0 & Not full publication \\
\hline Schell, E et al. EULAR 2003 Poster FRI0224 & 2 & Not full publication \\
\hline Benevolenskaya, L et al. EULAR 2003 Poster FRI0246 & 0 & Not full publication \\
\hline Grifka, JK et al. EULAR 2003 Poster FRI0222 & 0 & Not full publication \\
\hline Pavelka, K. EULAR 2005 Poster FRI0319 & 0 & Not full publication \\
\hline \multicolumn{3}{|l|}{ Clinical study reports } \\
\hline CSR105 & 5 & Study in patients with RA \\
\hline CSR110 & 5 & Study in patients with RA \\
\hline CSR111 & 5 & Study in patients with RA \\
\hline CSR 114 & 5 & Study in patients with RA \\
\hline CSR 2312 & 5 & Study in patients with RA \\
\hline CSR 2335 & 5 & Study in patients with RA \\
\hline CSR 2360E & 1 & No comparator \\
\hline CSR 2365 & 1 & No comparator \\
\hline CSR 2425 & 5 & Study in healthy subjects \\
\hline CSR 2427 & 5 & Study in patients undergoing knee surgery \\
\hline
\end{tabular}

$\mathrm{RA}=$ rheumatoid arthritis; $\mathrm{CV}=$ cardiovascular; EULAR $=$ European League Against Rheumatism; CSR $=$ Clinical Study Report

Randomised controlled trials of lumiracoxib versus other NSAIDs

There were 17 trials comparing lumiracoxib with other NSAID comparators. Of these, 12 studies reported any occurrence of APTC events in either group. There were sufficient data to perform meta-analysis for APTC events, MI, stroke and cardiovascular death. In total, there were 13,256 person-years' exposure to lumiracoxib and 10,964 person-years' exposure to other NSAID comparators within this group of studies.

There were 12 trials reporting any occurrence of APTC endpoints. In total, 78 events were reported in the lumiracoxib group $(n=17,434)$ and 58 events in the active NSAID comparator groups $(n=13,606)$. The pooled OR for the likelihood of APTC endpoints with lumiracoxib versus other NSAIDs was 1.16 (95\% CI 0.82, 1.63; Fig. 1). A sensitivity analysis, excluding 8 trials in which there were no events in either one of the lumiracoxib or comparator NSAIDs arms, showed a similar result (pooled OR 1.21, 95\% CI 0.84, 1.73).

Data for the MI endpoint were available in 7 trials with a total of $33 \mathrm{MI}$ events reported in 24,422 patients $(12,909$ in the lumiracoxib group and 11,513 in the other NSAIDs group). Overall, there was no significantly increased risk of MI for lumiracoxib users (pooled OR 1.66, 95\% CI 0.84, 3.29; Fig. 2). Six trials had only one MI event in either the lumiracoxib group or the other NSAID group. Farkouh et al. was the driving study for the pooled result.

Table 3 Antiplatelet Trialists' Collaboration (APTC) events in the lumiracoxib and placebo groups

\begin{tabular}{|c|c|c|c|c|c|}
\hline $\begin{array}{l}\text { Novartis study } \\
\text { number }\end{array}$ & $\begin{array}{l}\text { Reference } \\
\text { (if published) }\end{array}$ & $\begin{array}{l}\text { Number of patients in } \\
\text { the lumiracoxib group }\end{array}$ & $\begin{array}{l}\text { Number of patients } \\
\text { in the placebo group }\end{array}$ & $\begin{array}{l}\text { Number of APTC events } \\
\text { in the lumiracoxib group }\end{array}$ & $\begin{array}{l}\text { Number of APTC events } \\
\text { in the placebo group }\end{array}$ \\
\hline CSR109 & - & 925 & 231 & 1 & 0 \\
\hline CSR128 & - & 205 & 204 & 1 & 1 \\
\hline CSR2319 & - & 398 & 196 & 1 & 0 \\
\hline CSR2361 & [8] & 840 & 424 & 1 & 0 \\
\hline CSR2360 & [7] & 776 & 382 & 1 & 0 \\
\hline CSR112 & {$[10]$} & 978 & 243 & 1 & 0 \\
\hline Total & & 4,122 & 1,680 & 6 & 1 \\
\hline
\end{tabular}


Fig. 1 Meta-analysis of APTC endpoints in randomized controlled trials comparing steroidal anti-inflammatory lumiracoxib with other nondrugs (NSAIDs)

$\begin{array}{lcc}\text { Study } & \begin{array}{c}\text { Lumiracoxib } \\ \mathbf{n} / \mathbf{N}\end{array} & \begin{array}{c}\text { Other NSAID } \\ \mathbf{n} / \mathbf{N}\end{array} \\ & & \\ \text { CSR104 } & 1 / 925 & 0 / 444 \\ \text { CSR109 } & 3 / 830 & 1 / 405 \\ \text { CSR112 } & 1 / 524 & 1 / 518 \\ \text { CSR112E } & 1 / 205 & 0 / 102 \\ \text { CSR126 } & 0 / 144 & 1 / 145 \\ \text { CSR2303 } & 0 / 352 & 1 / 351 \\ \text { CSR2307 } & 0 / 427 & 2 / 419 \\ \text { CSR2316 } & 10 / 2277 & 2 / 759 \\ \text { Lehmann R 2005 } & 1 / 840 & 0 / 420 \\ \text { Sheldon E 2005 } & 1 / 776 & 0 / 393 \\ \text { Farkouh ME 2004 } & 59 / 9156 & 50 / 9169 \\ \text { Tannenbaum H 2004 } & 1 / 978 & 0 / 481 \\ \text { Combined } & 78 / 17434 & 58 / 13606 \\ \text { Q statistic P=0.99, I²=0\% } & \end{array}$

$\mathrm{Q}$ statistic $\mathrm{P}=0.99, \mathrm{I}^{2}=0 \%$

Stroke occurrence was rare within the trials studied. Only 3 trials were included in the meta-analysis (Fig. 3). The pooled OR for stroke was 0.95 (95\% CI 0.50, 1.76).

Eight trials reported cardiovascular death events and meta-analysis found no increased risk of cardiovascular death in the lumiracoxib group compared with the other NSAID group (Fig. 4; OR 1.04, 95\% CI 0.60, 1.80). A sensitivity analysis excluding 5 trials with no events occurring in either group resulted in a slightly higher estimate of the pooled OR (OR 1.11, 95\% CI 0.61, 2.01), but this remained statistically non-significant.

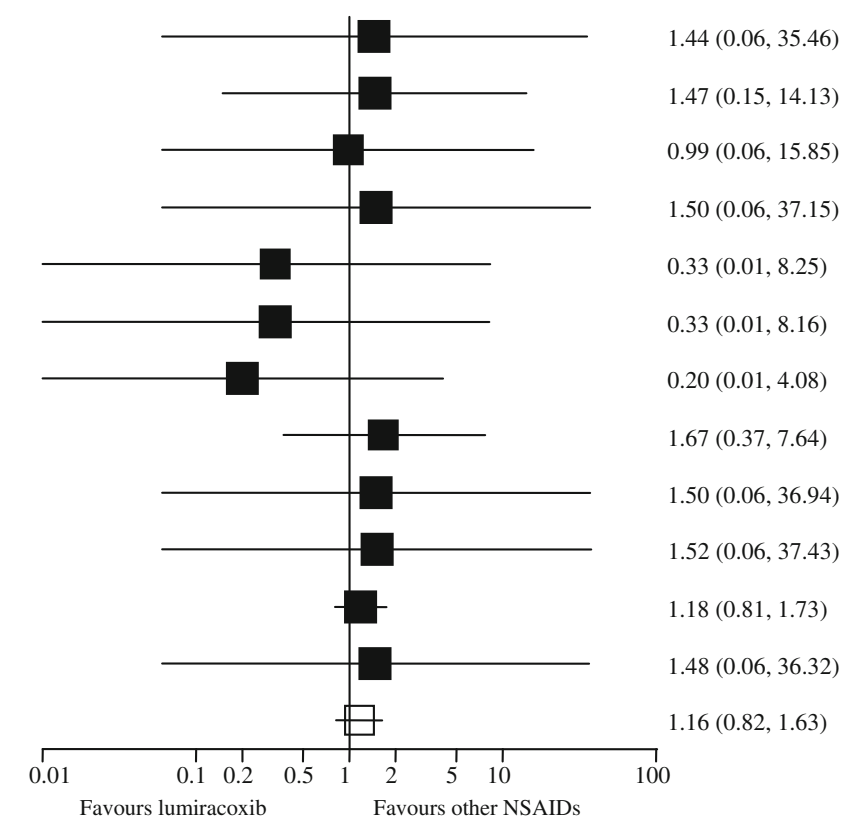

\section{Discussion}

Having reviewed the published and unpublished data available, it is apparent that while several clinical trials have been performed, we still have a paucity of data to judge the cardiovascular safety of lumiracoxib versus placebo or other NSAIDs, because cardiovascular events were rare in most of the studies. As far as we are able to judge from the data available, there is no evidence of increased risk of cardiovascular events with lumiracoxib versus placebo or versus other NSAIDs. However, for example for the MI endpoint, because of the wide confidence
Fig. 2 Meta-analysis of myocardial infarction (MI) events in randomized controlled trials comparing lumiracoxib with other NSAIDs

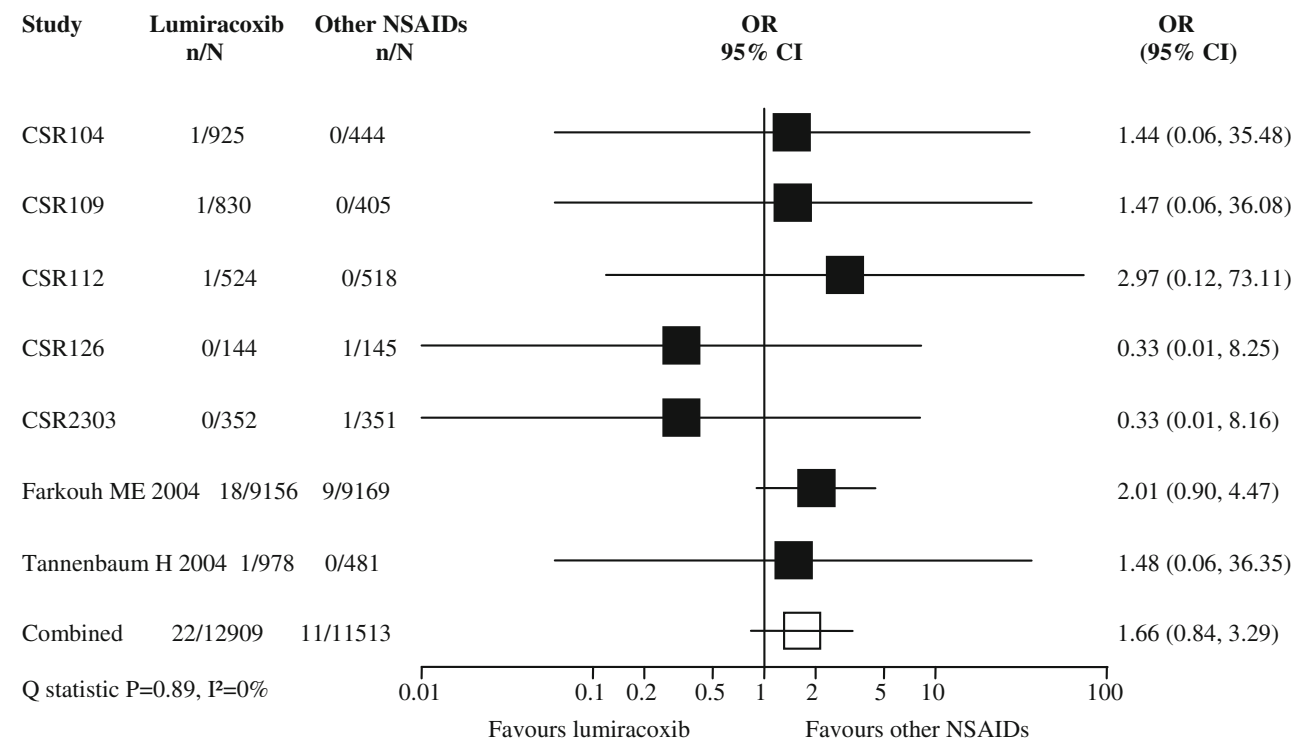


Fig. 3 Meta-analysis of stroke events in randomized controlled trials comparing lumiracoxib with other NSAIDs

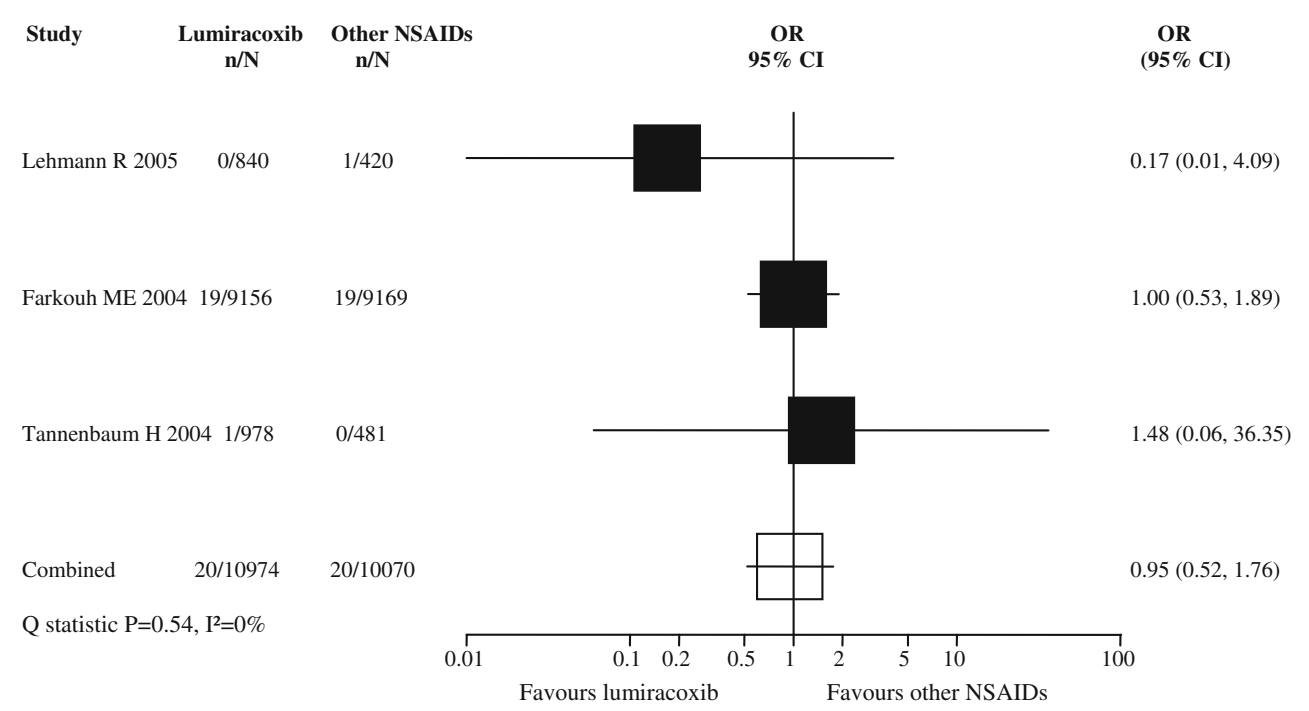

effects within either the lumiracoxib or NSAID comparator groups. While in several studies there is a trend towards some NSAIDs being safer, e.g. naproxen, and some being more harmful, e.g. rofecoxib, the mechanisms of increased risk are likely to be mixed and to include vascular, platelet and blood pressure effects. In patients with osteoarthritis, a risk-benefit judgement must be made to balance pain control and quality of life with any potential side effects of NSAIDs.

At least some of the blood pressure effects of NSAIDs are likely to be due to sodium retention [14]. Interestingly, while modest dietary salt restriction leads to significant reductions in systolic and diastolic blood pressures (average of up to 5 and $3 \mathrm{mmHg}$ respectively) in patients with hypertension $[15,16]$, a low salt diet leads to a much more striking reduction in blood pressure in patients with resistant hypertension (average 22.7 and $9.1 \mathrm{mmHg}$ reductions in office systolic and diastolic pressures respectively) [17]. Similarly, the potential benefits of lumiracoxib compared
Fig. 4 Meta-analysis of cardiovascular death events in randomized controlled trials comparing lumiracoxib with other NSAIDs

$\begin{array}{lcc}\text { Study } & \begin{array}{c}\text { Lumiracoxib } \\ \mathbf{n} / \mathbf{N}\end{array} & \begin{array}{c}\text { Other NSAIDs } \\ \mathbf{n} / \mathbf{N}\end{array} \\ \text { CSR109 } & 2 / 830 & 1 / 405 \\ \text { CSR112 } & 0 / 524 & 1 / 518 \\ \text { CSR112E } & 1 / 205 & 0 / 102 \\ \text { CSR2307 } & 0 / 427 & 2 / 419 \\ \text { CSR2316 } & 6 / 2277 & 1 / 759 \\ \text { Lehmann R 2005 } & 1 / 840 & 0 / 420 \\ \text { Sheldon E 2005 } & 1 / 776 & 0 / 393 \\ & & \\ \text { Farkouh ME 2004 } & 19 / 9156 & 18 / 9169 \\ \text { Combined } & 30 / 15035 & 23 / 12185 \\ \text { Q statistic P=0.95, I² }=0 \% & \end{array}$

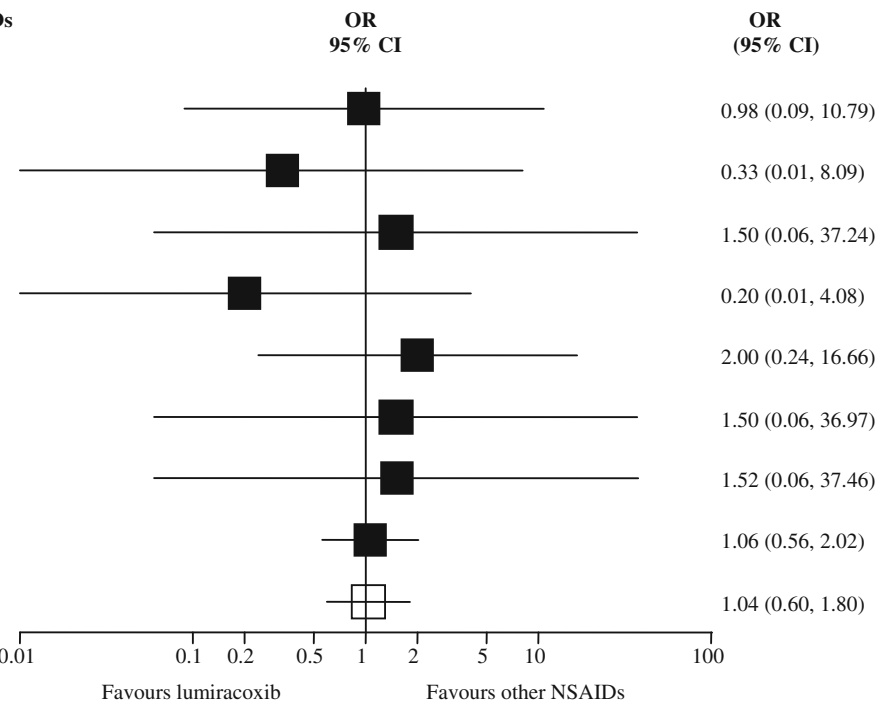


with other NSAIDs on blood pressure could be greatest in those patients with resistant hypertension. Therefore, lumiracoxib may be most beneficial for patients with osteoarthritis requiring NSAID therapy for pain control, but who also have resistant hypertension.

Limitations of our meta-analysis include the small number of cardiovascular events occurring in most of the trials. From the data, we calculated that the estimated incidences of APTC events for the active comparator group and the lumiracoxib group were 5.29 and 5.88 per 1,000 person-years respectively. It would require 29,486 person-years' exposure and 195 events to detect a $50 \%$ difference in the incidence of APTC events at a 5\% significance level and $80 \%$ power between lumiracoxib and other NSAIDs. Clearly our meta-analysis is not powered to detect such a difference. By including only higher quality trials (Jadad score $>3$ ) we may have excluded some other data, although one could argue that lower quality trials should not be included anyway. Our meta-analysis was limited to patients with osteoarthritis, who are generally thought to be at lower cardiovascular risk than patients with rheumatoid arthritis. A recent network meta-analysis including trials in patients taking NSAIDs for any medical condition found a statistically significant increase with lumiracoxib versus placebo in the rate ratio of stroke RR 2.81 (95\% CI 1.05-7.48) and of the APTC endpoint RR 2.04 (1.13-4.24), but no increased risk of MI, cardiovascular death or death of any cause [12]. Using the network meta-analysis technique to allow indirect comparisons between different NSAIDs, no statistically significant increase in risk of any of the above endpoints was found with lumiracoxib versus naproxen, etoricoxib, celecoxib, rofecoxib, diclofenac or ibuprofen.

\section{Conclusions}

The results suggest that the cardiovascular risk with lumiracoxib was not significantly different from that with placebo or with other NSAIDs. Wide confidence intervals mean that further research is needed in this area to confirm these findings.

Acknowledgements We acknowledge Xia Sheng, University of Dundee, for assistance with the statistical analysis and Chameleon Communications International for editorial services (providing copies of the study reports and Jadad scores).

Funding Novartis provided an unrestricted grant for editorial services from Chameleon Communications International.

Disclosures TMM has acted as a consultant for Novartis in relation to lumiracoxib and has received honoraria for giving educational lectures. He also serves as a consultant for Novartis with several other of their products. TMM holds research grants from Pfizer and TMM and ISM hold research grants from Pfizer, Menarini and Ipsen on behalf of the university sponsor. TMM, ISM and LW hold research grants from Novartis in a different therapeutic area which post-dates this work.

Author contributions ISM, LW and TMM were all involved in concept/design, data analysis and interpretation, drafting, critical revision and approval of the article.

Open Access This article is distributed under the terms of the Creative Commons Attribution License which permits any use, distribution, and reproduction in any medium, provided the original author(s) and the source are credited.

\section{References}

1. Kearney PM, Baigent C, Godwin J, Halls H, Emberson JR, Patrono C (2006) Do selective cyclo-oxygenase-2 inhibitors and traditional non-steroidal anti-inflammatory drugs increase the risk of atherothrombosis? meta-analysis of randomised trials. BMJ 332:1302-1308

2. MacDonald TM, Reginster J-Y, Littlejohn TW, Richard D, Lheritier K, Krammer G, Rebuli R (2008) Effect on blood pressure of lumiracoxib versus ibuprofen in patients with osteoarthritis and controlled hypertension: a randomized trial. J Hypertens 26:16951702

3. MacDonald TM, Richard D, Lheritier K, Krammer G (2010) The effects of lumiracoxib $100 \mathrm{mg}$ once daily versus ibuprofen $600 \mathrm{mg}$ three times daily on the blood pressure profiles of hypertensive osteoarthritis patients taking different classes of antihypertensive agents. Int J Clin Pract 64(6):746-755

4. Singer JB, Lewitzky S, Leroy E, Yang F, Zhao X, Klickstein L, Wright TM, Meyer J, Paulding CA (2010) A genome-wide study identifies HLA alleles associated with lumiracoxib-related liver injury. Nat Genet 42(8):711-714

5. Jadad AR, Moore RA, Carroll D et al (1996) Assessing the quality of reports of randomized clinical trials: is blinding necessary? Control Clin Trials 17:1-12

6. Farkouh ME, Kirshner H, Harrington RA, Ruland S, Verhuegt FWA, Schnitzer TJ, Burmester GR, Mysler E, Hochberg MC, Doherty M, Ehrsam E, Gitton X, Krammer G, Mellein B, Gimona A, Matchaba P, Hawkey CJ, Chesebro JH, on behalf of the TARGET Study Group (2004) Comparison of lumiracoxib with naproxen and ibuprofen in the Therapeutic Arthritis Research and Gastrointestinal Event Trial (TARGET), cardiovascular outcomes: randomised controlled trial. Lancet 364:675-684

7. Sheldon E, Beaulieu A, Paster Z, Dutta D, Yu S, Sloan VS (2005) Efficacy and tolerability of lumiracoxib in the treatment of osteoarthritis of the knee: a 13-week randomized, double-blind comparison with celecoxib and placebo. Clin Ther 27:64-77

8. Lehmann R, Brzosko M, Kopsa P, Nischik R, Kreisse A, Thurston $\mathrm{H}$, Litschig S, Sloan VS (2005) Efficacy and tolerability of lumiracoxib $100 \mathrm{mg}$ once daily in knee osteoarthritis: a 13-week, randomized, double-blind study vs. placebo and celecoxib. Curr Med Res Opin 21:517-526

9. Schnitzer TJ, Beier J, Geusens P, Hasler P, Patel SK, Senftleber I, Gitton X, Moore A, Sloan VS, Poor G (2004) Efficacy and safety of four doses of lumiracoxib versus diclofenac in patients with knee or hip primary osteoarthritis: a phase II, four-week, multicenter, randomized, double-blind, placebo-controlled trial. Arthritis Rheum 51:549-557 
10. Tannenbaum H, Berenbaum F, Reginster JY, Zacher J, Robinson J, Poor G, Bliddal H, Uebelhart D, Adami S, Navarro F, Lee A, Moore A, Gimona A (2004) Lumiracoxib is effective in the treatment of osteoarthritis of the knee: a 13 week, randomised, double blind study versus placebo and celecoxib. Ann Rheum Dis 63:1419-1426

11. Stricker K, Yu S, Krammer G (2008) A 6-week, multicentre, randomised, double-blind, double-dummy, active-controlled, clinical safety study of lumiracoxib and rofecoxib in osteoarthritis patients. BMC Musculoskeletal Disord 9:118

12. Trelle S, Reichenbach S, Wandel S, Hildebrand P, Tschannen B, Villiger PM, Egger M, Juni P (2011) Cardiovascular safety of NSAIDs: network meta-analysis. BMJ 342:c7086

13. Matchaba P, Gitton X, Krammer G, Ehrsam E, Sloan VS, Olson M, Mellein B, Hoexter G, Orloff J, Garaud J (2005) Cardiovascular safety of lumiracoxib: a meta-analysis of all randomized controlled trials $>$ or $=1$ week and up to 1 year in duration of patients with osteoarthritis and rheumatoid arthritis. Clin Ther 27(8):1196-1214

14. Mackenzie IS, MacDonald TM (2010) Treatment of osteoarthritis in hypertensive patients. Expert Opin Pharmacother 11(3):393-403

15. Hooper L, Bartlett C, Davey SG, Ebrahim S (2004) Advice to reduce dietary salt for prevention of cardiovascular disease. Cochrane Database Syst Rev (1):CD003656

16. He FJ, MacGregor GA (2004) Effect of longer-term modest salt reduction on blood pressure. Cochrane Database Syst Rev (3): CD004937

17. Pimenta E, Gaddam KK, Oparil S, Aban I, Husain S, Dell'Italia LJ, Calhoun DA (2009) Effects of dietary sodium reduction on blood pressure in subjects with resistant hypertension. Hypertension $54: 475-481$ 